\title{
Evaluation of genetic diversity between toxic and non toxic Jatropha curcas $L$. accessions using a set of simple sequence repeat (SSR) markers
}

\author{
Massimo Vischi* ${ }^{*}$ Steluta Raranciuc and Mario Baldini \\ Dipartimento di Scienze Agrarie e Ambientali, Università di Udine, via delle Scienze 208, 33100 Udine, Italy.
}

Accepted 8 January, 2013

\begin{abstract}
Scepticism about Jatropha as a competitive biofuel feedstock especially on marginal soils has been growing; in fact, the jatropha-biofuel chain is risky economically and often financially unfeasible without significant government subsidies under these conditions. A valorization of the by-products and in particular of the extruded seed cake (about $70 \%(w / w)$ of the processed seed), as animal feed, currently prevented by the presence of phorbol esters (PE) toxins, could contribute to a significant improvement in the economic sustainability of the crop. Strategies for breeding improved varieties could be accelerated by DNA-based molecular marker technology. Wild Mexican accessions and accessions from other parts of the world (South America and Africa) were analyzed by 40 simple sequence repeat (SSR) markers. SSR primers were chosen on the grounds of their Tm, length, degree of polymorphism and specificity for toxic trait. The genetic study pointed out a high degree of similarity both within and among the non Mexican accessions. The Mexican accessions proved to be non toxic and genetically differentiated forming a well separated cluster from out of Mexico accessions. Some polymorphic loci were close correlated with the character toxicity and useful, once validated their association in segregating populations for Marker Assisted Selection (MAS).
\end{abstract}

Key words: Jatropha curcas, genetic variability, molecular markers, non-toxic accession, phorbol esters, simple sequence repeat (SSR) genotyping.

\section{INTRODUCTION}

Jatropha curcas L. has received increasing interest in the last years as a new biofuel crop due to its potential use in the so-called "marginal areas", where there is no competition with food crops, as usually occurs on more fertile land (Tiwari et al., 2007; Prasad et al., 2012). The plant is a shrub/perennial tree producing high quality oil. It is resistant to high temperatures, drought, pests and diseases, with low nutritional input and a well-developed

* Corresponding author. E-mail: massimo.vischi@uniud.it. Tel: +390432558609. Fax: +390432558603.

Abbreviations: AFLP, Amplified fragment length polymorphism; EST, expressed sequence tag; ISSR, inter simple sequence repeat; $\mathbf{T m}$, melting temperature. rooting system to protect soil from erosion (Ceasar and Ignacimuthu, 2011). It is widely cultivated in Asia, Latin America and Africa, the International Jatropha Organization (Siddharth and Sharma, 2010), forecast a strong expansion of this crop in the near future up to 12.8 million ha worldwide in 2015. An increase in seed yield and oil content remains the main goal of genetic improvement of $J$. curcas, but a wider acceptability of the whole jatropha-biofuel chain can only be fully achieved with the utilization of the seed cake (about $65-75 \% \mathrm{w} / \mathrm{w}$ of the processed seed) as animal feed. Its use is limited by the presence of phorbol esters (PE), which are highly toxic for animals even at very low concentrations and resistant to high temperature (Makkar and Becker, 2009; Baldini et al., 2012). In the near future, the solution may come from non-toxic J. curcas accessions. These genotypes of Mexican origin can be used in breeding 
programmes to recombine non-toxic traits into elite (toxic) varieties. Strategies for breeding improved varieties could be accelerated by DNA-based molecular marker technology. In the last years different classes of molecular markers have been developed to analyse the germplasm of $J$. curcas.

Different classes of universal molecular markers such as random amplified polymorphic DNA (RAPD), inter simple sequence repeat (ISSR), and amplified fragement length polymorphism (AFLP) were used initially. Sujatha et al. (2005) calculated a similarity index between toxic Indian varieties and a non-toxic variety of Mexican origin by means of about 400 RAPD markers. The similarity index was about $95 \%$, plus their crossing studies pointed out a maternal effect on PE content of seeds. Other studies with RAPD and ISSR markers show high genetic diversity in Mexican germplasm and low genetic variation in accessions from other countries in terms of both $\mathrm{PE}$ levels and molecular profiles (Basha et al., 2009). The AFLP analysis indicated that there was very little genetic diversity in the material obtained from Madagascar, Tanzania and Suriname. For a large subset of these samples, no polymorphisms were observed, suggesting that this material is almost clonal. Within the Mexican samples genetic diversity was relatively high, with a total of 85 polymorphic bands being observed (PPB25.2\%) (He et al., 2011).

Microsatellites or simple sequence repeats (SSRs) were the second generation of markers used in J. curcas because of their co-dominant nature, abundance in genomes, high reproducibility, hyper polymorphism and high rates of transferability across species/genera. SSRs were developed both from genomic DNA libraries and in silico as expressed sequence tag (EST)-SSR. Wen et al. (2010) tested the transferability of 419 EST-SSR and 182 G-SSR primer pairs between Cassava and five accessions of $\mathrm{J}$. curcas. Among these primers, 234 $(55.85 \%)$ EST-SSR and 68 (37.36\%) Genomic-SSR primer pairs produced amplicons, but only 187 (44.63\%) EST-SSRs and 54 (29.67\%) Genomic-SSRs were polymorphic among the five accessions. Yadav et al. (2011) assembled 1227 contigs from 13201 expressed sequence tags (ESTs) of J. curcas from the National Center for Biotechnology Information database. Four hundred and six primer pairs were designed out of the 702 SSR-containing sequences. Fifty randomly selected EST-SSR markers were amplified in 25 accessions collected from different geographical regions of India. Polymorphic information content value ranged between 0.04 and 0.61 with an average of $0.25 \pm 0.16$, indicating low to moderate level of informativeness within these EST-SSRs.

SSRs were also developed from enriched genomic libraries. Phumichai et al. (2011) isolated 55 microsatellite markers, among these 11 were polymorphic when tested in 26 accessions of $J$ curcas from Thailand. One use of molecular markers regards the possibility of discriminating the toxic from the non-toxic varieties, given that no significant morphological, qualitative or quantitative differences are known between these except for the PE content in the toxic varieties (Commission of the European Communities, 2007; Sahoo and Das, 2009). Given that the SSRs are the markers of choice for this analysis, we used them to evaluate the level of polymorphism and the capacity to discriminate between the toxic and non-toxic accessions of a sample of primers chosen from those published, developed both from enriched genomic libraries and from EST databases.

\section{MATERIALS AND METHODS}

\section{Plant material}

A total of 29 accessions were collected from America (North, Central, South) and Africa starting in 2009. They included 19 populations from different geographical areas in Mexico. The seed of each accession (one to four individuals per accession) was carefully characterized for PE content. The complete list of populations with their provenance and PE content is reported in Table 1.

\section{Phorbol esters extraction and analysis}

Sample preparation and PE extraction was done according to the method of Makkar et al. (2007). Briefly, the fruit seeds were predried before de-hulling and drying at $100-105^{\circ} \mathrm{C}$ for $30 \mathrm{~min}$. Five kernels of each variety were ground and $2 \mathrm{~g}$ of kernel powder was subjected to PE extraction by methanol. The methanol extraction step was repeated three times with sonication and centrifugation at $3000 \mathrm{~g}$ for $8 \mathrm{~min}$ at room temperature. PE concentration was obtained by methanol evaporation using a rotary evaporator at $40^{\circ} \mathrm{C}$ and by flushing with nitrogen. The obtained sample was adjusted to the final volume of $2 \mathrm{ml}$ with methanol, filtered and injected manually $(20 \mu \mathrm{L})$ into the high performance liquid chromatography (HPLC).

\section{HPLC conditions for quantification of phorbol esters}

The analysis was conducted according to the method of Haas and Mittelbach (2000). The HPLC instrument was equipped with a vacuum degasser and a variable UV-VIS wavelength detector (BioRad 1801, Bio-Rad Laboratories, USA). The separation was performed on a $150 \times 4.6 \mathrm{~mm}$ Poroshell 120 EC-C18 column packed with $2.7 \mu \mathrm{m}$ particles (Agilent Technologies, USA). 80\% acetonitrile solution (HPLC grade, Sigma-Aldrich, Germany) was used as eluent at a flow rate of $2 \mathrm{ml} / \mathrm{min}$ at $25^{\circ} \mathrm{C}$. The detector wavelength was set at $280 \mathrm{~nm}$. A calibration curve was prepared using phorbol 12-myristate 13-acetate (12-O Tetradecanoylphorbol 13-acetate, TPA, Sigma, Germany) as an external standard (Wink et al., 1997). The detection limit was calculated as: $y=y_{B}+3 s_{B}$, where $y$ is the detection limit, $y_{B}$ is the blank signal and $s_{B}$ is standard deviation of the blank. The detection limit was $1.0 \mathrm{mg} \mathrm{kg}^{-1}$.

\section{SSR genotyping}

Seed coats were removed from seeds after a preliminary imbibition 
Table 1. Jatropha curcas accessions used for genetic analysis with SSR markers. The table indicates the origin and the seed kernel content of phorbol esters (PE) expressed as equivalent to a standard, phorbol-12-myristate 13-acetate (limit of detection $1 \mathrm{mg} \mathrm{kg}^{-1}$ ).

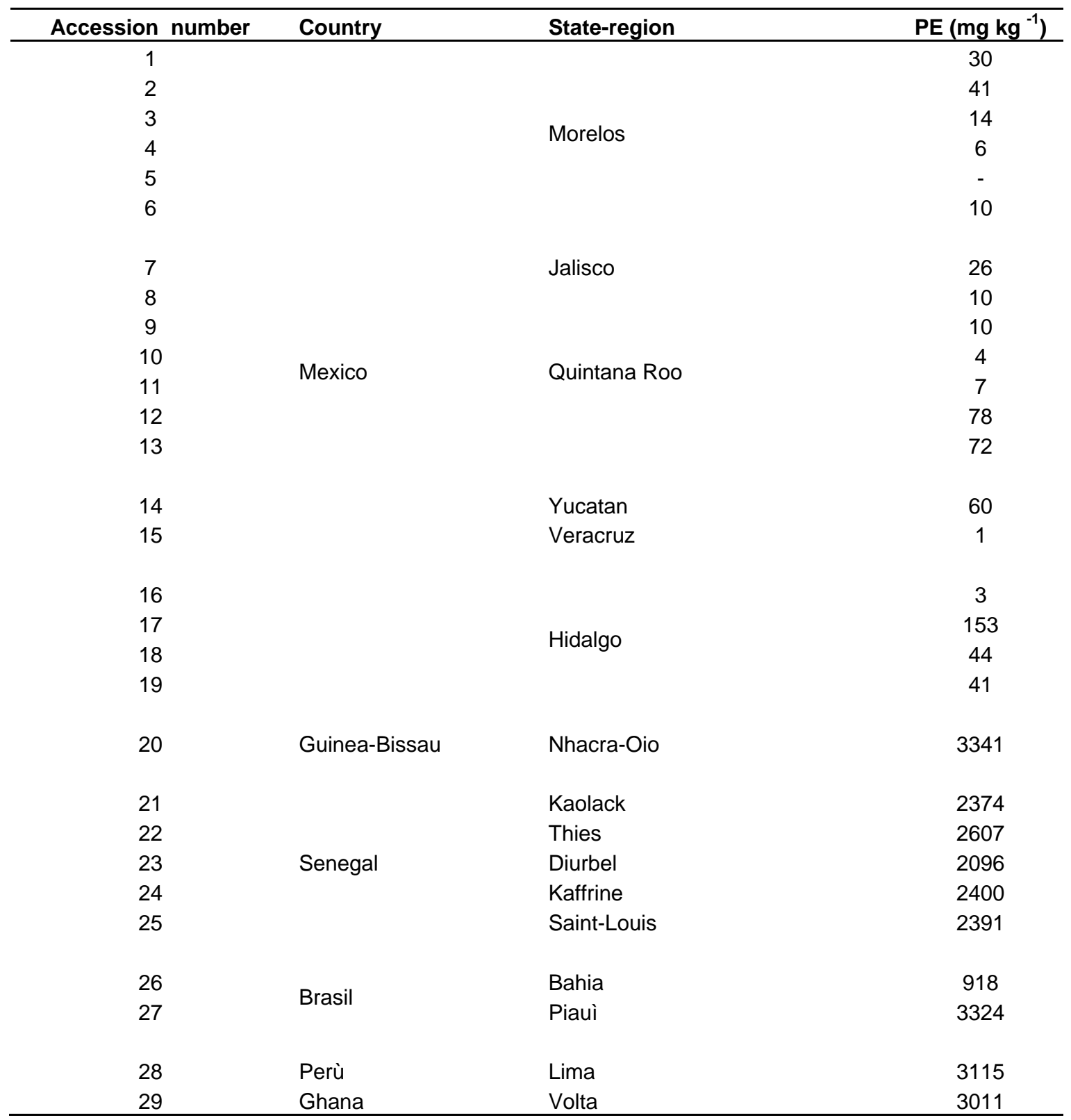

-, Not detected.

in water for $24 \mathrm{~h}$. Separated cotyledons were ground into a powder in the presence of liquid nitrogen: DNA was extracted from 2-4 individuals per accession using the Dneasy 96 Plant Mini Kit (Qiagen $\mathrm{GmbH}$, Hilden, Germany). A total of forty pairs of primers were used. The primers were chosen on the grounds of their Tm, length, degree of polymorphism and specificity for toxic varieties from those published by Pamidimarri et al. (2009), Phumichai et al. (2011), Yadav et al. (2011), Wen et al. (2010) and Basha et al. (2009). The complete list of primers is reported in Table 2.

A tailed polymerase chain reaction (PCR) primer was used for SSR analysis by adding a 19-base M13 oligo sequence (M13 tail) to the 5' end of each forward SSR primer. Thus, each SSR reaction used three primers: two unlabelled SSR primers with one having an attached M13 sequence tail, and one universal M13 primer labelled with $\mathrm{FAM}$ with the same sequence as the tail sequence attached to one of the SSR primers (Schuelke, 2000; Boutin-Ganache et al., 2001; Fukatsu et al., 2005). The PCR reaction was carried out in 10 $\mu \mathrm{L}$ of a solution containing $10 \mathrm{ng}$ genomic DNA, $1 \times$ Mg-free PCR buffer solution, $0.25 \mathrm{mM}$ dNTPs, $1.5 \mathrm{mM} \mathrm{MgCl}_{2}, 0.15 \mathrm{pmol}$ forward primer, 0.3 pmol reverse primer, 0.3 pmolM13-labelled primer, 0.5 $\mathrm{U}$ AmpliTaq Gold DNA polymerase (Applied Biosystems) and $\mathrm{dH}_{2} \mathrm{O}$. Amplification was performed in a 9700 Thermal Cycler (Applied Biosystems) as follows: $5 \mathrm{~min}$ at $95^{\circ} \mathrm{C}$ followed by 30 cycles of: $30 \mathrm{~s}$ at $94^{\circ} \mathrm{C}, 45 \mathrm{~s}$ at $55^{\circ} \mathrm{C}, 45 \mathrm{~s}$ at $72^{\circ} \mathrm{C}, 8$ cycles of: $30 \mathrm{~s}$ at $94^{\circ} \mathrm{C}, 45 \mathrm{~s}$ 


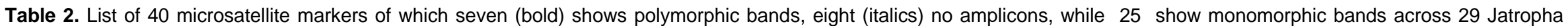
accessions.

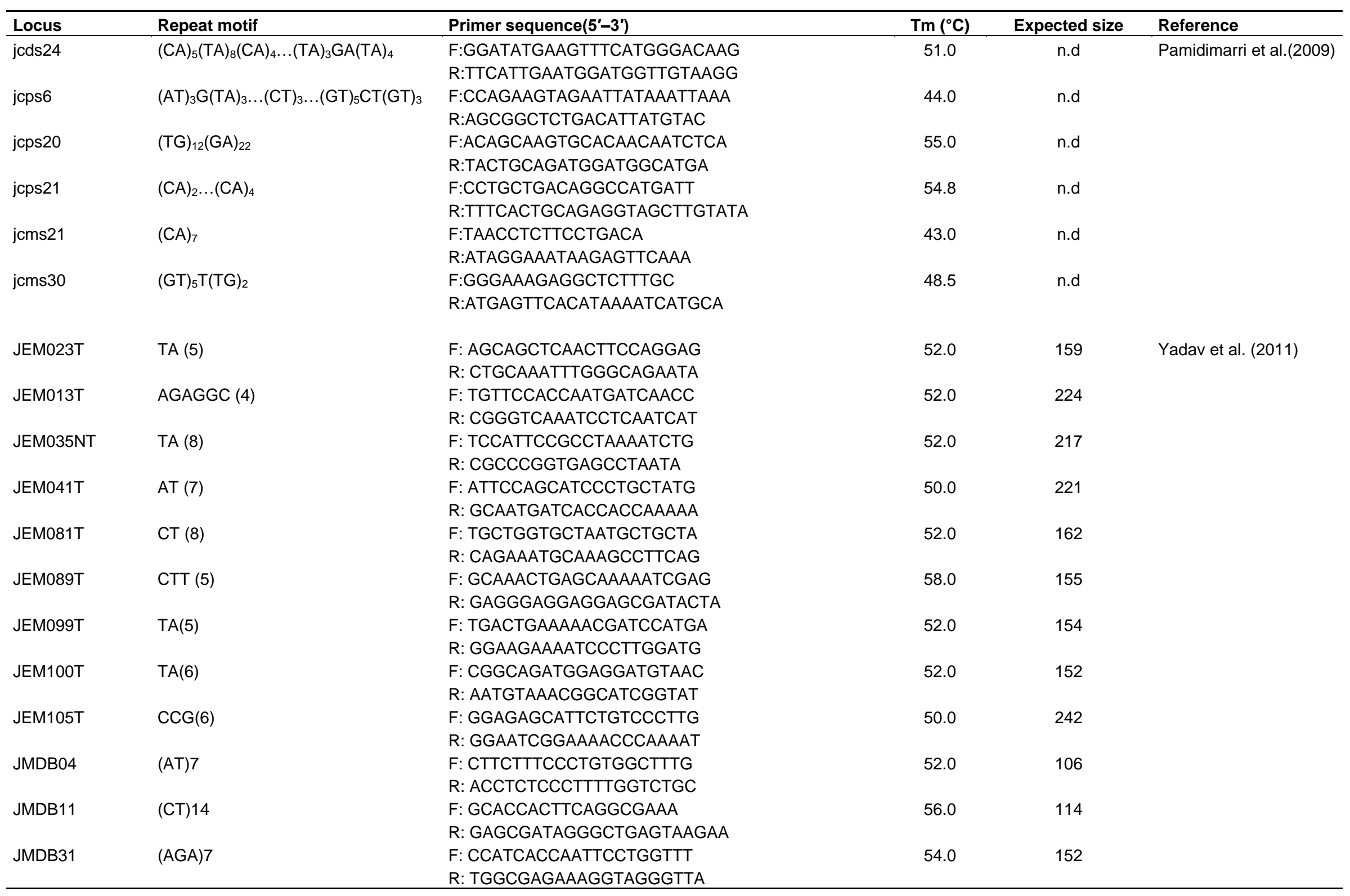


Table 2. Continued.

\begin{tabular}{|c|c|c|c|c|c|}
\hline \multirow[t]{2}{*}{ JMDB38 } & $(\mathrm{TC}) 11$ & F: GGCCCTTTACAATTTTCTACTGTC & 54.0 & 181 & \\
\hline & & R: GCAGACACGATTTTCCGACT & & & \\
\hline \multirow[t]{2}{*}{ JMDB57 } & $(\mathrm{AAT}) 8$ & F: TGGCAGAGCAACTGCAAATA & 56.0 & 187 & \\
\hline & & R: TCTCACACACCCCAAATTCA & & & \\
\hline \multirow[t]{2}{*}{ JCT16 } & (GT)11 & F: GCCTCCAGCATCTTTCAATC & 60.0 & n.d & Phumichai et al. (2011) \\
\hline & & R: AАСААТССССАТТССТССТС & & & \\
\hline \multirow[t]{2}{*}{ JCT27 } & $(\mathrm{CT}) 17$ & F: GCCATTAGAATGGACGGCTA & 60.0 & n.d & \\
\hline & & R: TGCGTGAAGCTTTGATTTGA & & & \\
\hline \multirow[t]{2}{*}{ JCT31 } & (TC) 18 & F: TGGAAAACGAATGAGGCTCT & 59.0 & n.d & \\
\hline & & R: GGACACTCTGGAAAGGAACG & & & \\
\hline \multirow[t]{2}{*}{ JCT37 } & (AG)20 & F: ATTCGACAATCTACGGGATA & 54.0 & n.d & \\
\hline & & R: CACCTTATACGTCTCTCTCTCTC & & & \\
\hline \multirow[t]{2}{*}{ JCT81 } & (CT) 18 & F: CCATTTAGAACCACAACCAT & 540. & n.d & \\
\hline & & R: GATGTCCAATAAGCCTGAAT & & & \\
\hline \multirow[t]{2}{*}{ JCT86 } & $(\mathrm{GA}) 17$ & F: TATTTCСTCTTCСTGСАСАT & 56.0 & n.d & \\
\hline & & R: GTTTGGCTAAAAAGGTGATG & & & \\
\hline \multirow[t]{2}{*}{ JCT89 } & (CT) 16 & F: GCCGATAAACCACAGATAAA & 54.0 & n.d & \\
\hline & & R: GAAAAATAAAGCCAGCAAGA & & & \\
\hline \multirow[t]{2}{*}{ JCT103 } & $(A G) 17$ & F: CAACGACTCTTTGAAGAAAAA & 54.0 & n.d & \\
\hline & & R: GCCGATAAACCACAGATAAA & & & \\
\hline \multirow[t]{2}{*}{ JGAA1 } & $(\mathrm{GAA}) 9$ & F: AAAGGTCACAGTGTTTCAAAG & 56.0 & n.d & \\
\hline & & R: TTCTTTCTСААСТTССТССА & & & \\
\hline \multirow[t]{2}{*}{ JSSR-225 } & $\mathrm{di}-$ & F: CGCAAGGTAAATCGGAGCTA & 55.0 & 117 & Wen et al. (2010) \\
\hline & & R: ACAATCAAAGGAGTCGTGTAATC & & & \\
\hline \multirow{2}{*}{ JSSR-228 } & $\mathrm{di}-$ & F: TAGAGCAGCTGCAAAGCAAA & 55.0 & 169 & \\
\hline & & R: TCGTTTTCCTGTTGAAATCTTG & & & \\
\hline \multirow[t]{2}{*}{ JSSR-232 } & $\mathrm{di}-$ & F: CAGGACATGACGCAATTCTG & 55.0 & 247 & \\
\hline & & R: GCATGTTAGAAGTTTTTGCAATTT & & & \\
\hline \multirow[t]{2}{*}{ JSSR-233 } & $\mathrm{di}-$ & F: CTTTTTGCCAGTCTTCCTGC & 55.0 & 205 & \\
\hline & & R: AATGGATCATGTTCAATGTCTTC & & & \\
\hline \multirow{2}{*}{ JSSR-236 } & $\mathrm{di}-$ & F: CGACTGCATCAGAACAATGC & 55.0 & 296 & \\
\hline & & R: AGCATGTCATTGCACCAAAC & & & \\
\hline \multirow{2}{*}{ JSSR-237 } & $\operatorname{tri}-$ & F: CAGTGAGCAGAAACTAAAAACATTG & 55.0 & 212 & \\
\hline & & R: GGCACTTTGGAAAGGAAGAG & & & \\
\hline \multirow[t]{2}{*}{ JcSSR-19 } & $(\mathrm{AC}) 21$ & F: CTTGAAAGTTTTTGTAATTTC & 50.0 & 214 & Basha et al. (2009) \\
\hline & & R: CGCCAATCATAGATC & & & \\
\hline
\end{tabular}


Table 2. Continued.

\begin{tabular}{|c|c|c|c|c|}
\hline \multirow{2}{*}{ JcSSR-20 } & $(\mathrm{AC}) 10$ & F: GGCTGAACTTGCGCC & 60.0 & 260 \\
\hline & & R:GCCCTGATTTCTGGTC & & \\
\hline \multirow[t]{2}{*}{ JcSSR-21 } & $(\mathrm{C}) 7(\mathrm{~A}) 5(\mathrm{CA}) 9$ & F: CTGAAATGGAGAAATTGG & 50.0 & 249 \\
\hline & & R: ACATATCGAAGATAGGG & & \\
\hline \multirow[t]{2}{*}{ JcSSR-22 } & (TC) 16 & F: GAATCTCAACAGTGCCC & 52.0 & 152 \\
\hline & & R: GAAGGATGGGAAGTGGG & & \\
\hline \multirow[t]{2}{*}{ JcSSR-26 } & $(\mathrm{CA}) 18$ & F: CATACAAAGCCTTGTCC & 55.0 & 211 \\
\hline & & R: AACAGCATAATACGACTC & & \\
\hline
\end{tabular}

at $53^{\circ} \mathrm{C}, 45 \mathrm{~s}$ at $72^{\circ} \mathrm{C}$ and a final extension stage of $10 \mathrm{~min}$ at $72^{\circ} \mathrm{C}$. PCR products were separated with an ABI 3730 DNA sequencer (Applied Biosystems) and the fragments were sized by means of a ladder labelled with a fluorochrome VIZ (LIZ500 Applied Biosystems). Data were analysed with GeneMarker software (Version 2.2.0, SoftGenetics).

\section{Statistical analysis}

GenAIEx6 software (Peakall and Smouse, 2006) was used to estimate allele number (An), expected heterozygosity $(\mathrm{He})$, number and frequency of genotypes for each accession. Polymorphism information content (PIC) was computed for each SSR locus according to the study of Botstein et al. (1980). Nei's (1983) genetic distance was calculated in the Populations software program (Langella, 1999). A cluster diagram was constructed based on these distances by the unweighted pair-group method using arithmetic averages (UPGMA) (Sneath and Sokal, 1973) with the UPGMA tree searching algorithm of the software. A thousand replicate distance matrices were bootstrapped (Felsenstein, 1985) to evaluate the robustness of the trees. The tree file was visualized and manipulated using the software MEGA version 5 (Tamura et al., 2011).

\section{RESULTS AND DISCUSSION}

\section{PE content}

The levels of PE in the accessions not coming from Mexican areas (Table 1) varied from a minimum of 919 (just one genotype collected in Bahia, Brazil) up to a maximum of $3341 \mathrm{mgkg}^{-1}$, with an average of $2558 \mathrm{mgkg}^{-1}$, confirming that PE present at levels of 2000 to $4000 \mathrm{mgkg}^{-1}$ are typical of "toxic" accessions and these are prevalent throughout the world (Rakshit et al., 2010; Makkar and Beker, 2009). On the contrary, all accessions collected in Mexico have shown values between 1 and $78 \mathrm{ppm}$, with several accessions very close to the detection limit (1 $\mathrm{mgkg}^{-1}$ ) and just one (collected in Hidalgo) exceeded $100 \mathrm{mgkg}^{-1}$; this level is considered the maximum threshold for seeds categorized as "edible" or "non-toxic" (Makkar et al., 1998). The above results confirm that the non-toxic genotypes exist only in Mexico and some of these are better than the conventional toxic jatropha varieties in seed yield and seed oil content (Francis et al., 2013). These genotypes could be directly utilized as seed cake, in animal feeding, after mechanical oil extraction.

\section{SSR analysis}

The data obtained were classified according to a qualitative scale, with scores ranging from 1 to 5 , describing the complexity of the amplification profile for each primer (Stephenson et al., 1998). Of the 40 loci considered, 26 of them generated an electropherogram of a single locus, of easy interpretation as stuttering was absent or very slight (score 1,2), in 6 loci the presence of irregular stutter bands and/or multilocus peaks hindered reliable interpretation (score 4, 5), the last 8 loci failed to give rise to amplification products. Despite the good quality of 26 loci, only 7 of them revealed polymorphism across the populations considered in this study. The 7 loci revealed a total of 16 alleles in the $29 \mathrm{~J}$. curcas accessions. The seven polymorphic microsatellite markers and their properties are reported in Table 3. An overview of SSR markers as detected by DNA fragment analysis with a fully automated capillary electrophoresis system is given in Figure 1. The number of alleles per locus was very limited, ranging from 2 (JMDB04, JCT16, JcSSR26, JCT27, JCT31, JCT81) to 3 (jcms21). The average PIC (Polymorphism Information Content) value was 0.3617 within the range 0.351 (JCT27) to 0.389 (jcms21). The loci were completely or highly homozygotic and consequently the alleles were fixed.

\section{Genetic relationships between accessions}

The genetic distance between the accessions examined was calculated using Nei's index (1983). Cluster analysis applied to the matrix 
Table 3. List of the seven polymorphic loci and their proprieties.

\begin{tabular}{llcccccc}
\hline LOCUS & Accession & $\mathbf{N a}^{\mathbf{a}}$ & $\mathbf{H o}^{\mathbf{b}}$ & $\mathbf{H e}^{\mathbf{c}}$ & $\mathbf{P I C}^{\mathbf{d}}$ & Allele size (bp) non-toxic $^{\text {Allele size (bp) toxic }}$ \\
\hline jcms21 & EU586350 & 3 & 0.015 & 0.4912 & 0.388 & $90-92$ & 78 \\
JMDB04 & JMDB04 & 2 & 0.000 & 0.4632 & 0.354 & 125 & 123 \\
JCT16 & AB512288 & 2 & 0.000 & 0.5027 & 0.374 & 120 & 122 \\
JCT27 & AB512290 & 2 & 0.000 & 0.4576 & 0.351 & 259 & 253 \\
JcSSR-26 & (EU099526) & 2 & 0.000 & 0.4632 & 0.354 & 210 & 230 \\
JCT31 & AB512291 & 2 & 0.000 & 0.4663 & 0.355 & 214 & 208 \\
JCT81 & AB512296 & 2 & 0.000 & 0.4632 & 0.354 & 157 & 161 \\
\hline
\end{tabular}

a, number of alleles; b, observed heterozygosity; c, expected heterozygosity; d, polymorphism information content; bp, base pairs.
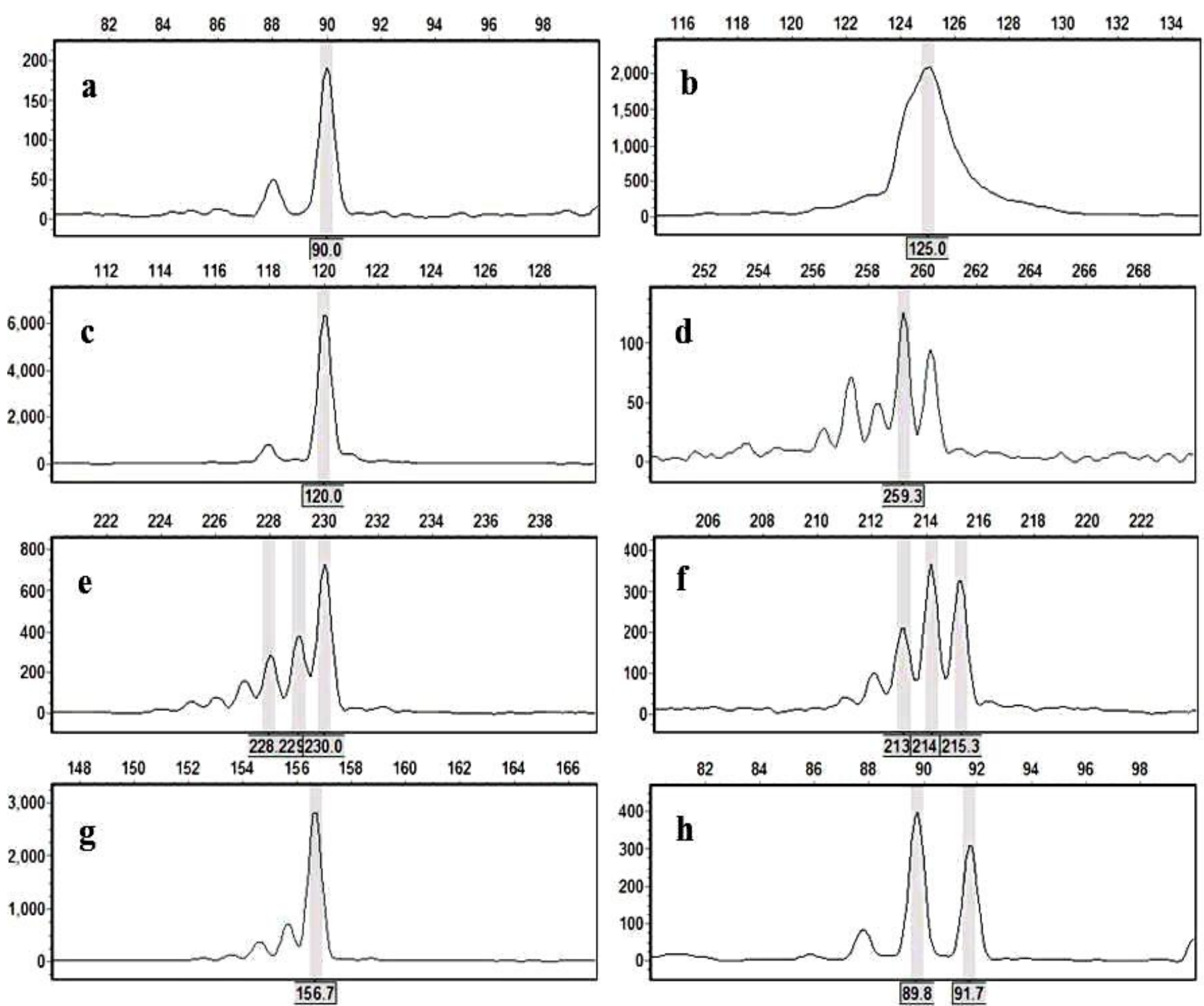

Figure 1. DNA fragment profiles of some alleles displayed by the 7polymorphic loci. The non Mexican accessions proved to be homozygous in all loci. (a, Jcms21; b, JMBD04; c, JcSSR16; d, JCT27; e, JcSSR26; f, JCT31; g, JCT81). The Mexican accessions were highly homozygous with some exception (h, Jcms21). To note the heterozygous locus for alleles of 90 and 92 bp. a, b, d, f, specific alleles (90, 125, 259, 214 bp respectively) for Mexican accessions, e. g. specific alleles (230, 160 bp respectively) for non Mexican accessions. 


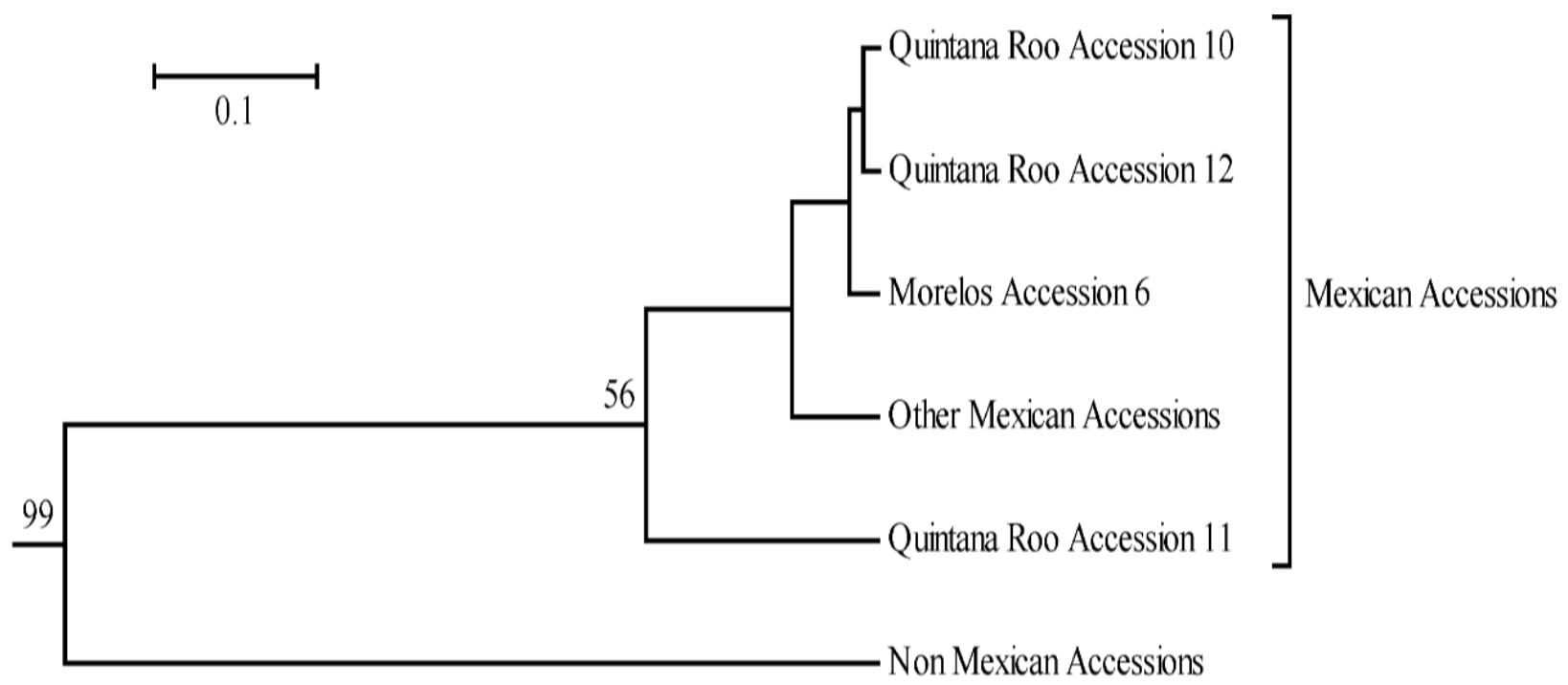

Figure 2. UPGMA cluster analysis of $J$. curcas accessions based on Nei's genetic distances. Only values above $50 \%$ of bootstrap node support are shown. Accession numbers are reported as in Table 1.

of genetic distances produced a diagram in which two branches are created that identify two completely different clusters, each of which is composed of very similar populations (Figure 2). The first group includes the non-Mexican toxic populations and the second, the nontoxic Mexican populations. Strong genomic uniformity was found within non-Mexican group of accessions. Some genetic variability was noted in the Mexican group, the accessions 10, 12 from Quintana Roo and accession 6 from Morelos regions were on separated branches from the other Mexican accessions. Moreover accession 11 from Quintana Roo Region formed a distinct sub-group supported by a bootstrap value greater than 50 (Figure 2). These results pointed out Quintana Roo region as the most promising area for genetic variability of $J$. curcas. The high homozygosis is surprising in a monoic and allogamous species but in agreement with previous reports by Ambrosi et al. (2010), Rosado et al. (2010) and Tanya et al. (2011) who found high values of homozygosis estimated on the basis of co-dominant SSR markers, especially in non-Mexican accessions. The species is a native to Central and South America, but is now widely present throughout Central America, Africa and Asia. Limited genetic variation of J. curcas populations outside the centre of origin is likely due to infrequent introductions, predominant vegetative propagation or the occurrence of asexual reproduction (that is, apomixis) (Ambrosi et al., 2010). This restricted genetic base generates phenomena of inbreeding that could explain the high homozygosis (Rosado et al., 2010).

Out of 7 polymorphic loci, jcms21 (EU586350), JMDB04, JCT27 (AB512290), JCT31 (AB512291), JCT81 (AB512296) and JcSSR-26 (EU099526) clearly displayed distinct allele patterns between 19 Mexican accessions (nontoxic) versus 10 non-Mexican accessions (toxic) (Table 2), with the only exception being JCT16 (AB512288) that shared 2 alleles in both groups. Interestingly, loci jcms21 (EU586350) and JcSSR-26 (EU099526) displayed specific alleles for each geographical group well differentiated in length (78 vs. 90 bp and 210 vs. $230 \mathrm{bp}$, respectively). According to a Stepwise Mutation Model this implies a well separated evolutionary history that could strengthen the hypothesis that the current distribution of $J$. curcas is not only a result of recent human activity but is also due to the historical separation and the subsequent spreading of Jatropha in Africa and America (Dehgan and Webster, 1979; Dehgan and Schutzman, 1994). The high homozygosis and low genetic variability found also in the Mexican accessions may at least in part be explained by the fact that the samplings were done on isolated plants distant from other possible pollinators and this has led to a high inbreeding over the years with the consequent fixation of the alleles. The low genetic variability found between the Mexican accessions may instead be due to the limited number of markers and that those polymorphic are anyway associated to the toxicity as described in materials and methods. In order to find greater variability, further samplings should be carried out in different Mexican areas. As already reported by Ovando-Medina et al. (2011), a high genetic diversity was found within and among J. curcas populations in the State of Chiapas. These markers could be utilized to easily identify the toxic varieties from that non-toxic given that no particular morphological differences exist (Pamidimarri et al., 2009). The association to toxicity should anyhow be validated with the development of segregating populations and the construction of genetic maps to avoid spurious associations on a geographical basis rather than genetic. 
These markers could then be utilized for programmes of selection assisted by markers to introduce the nontoxicity character in elite varieties of J.curcas.

The sustainability and hence wider acceptance of the jatropha-based biofuel chain will be fully achieved only with the utilization of the $J$ seed cake as animal feed. The successful solution could be to obtain a non-toxic $J$. curcas plant, starting from the accessions already present in Mexico improved by suitable breeding programmes or utilized as a genetic source for the introgression of the non-toxic trait into elite toxic varieties. So a primary goal in the genetic improvement of $J$. curcas will be the identification of accessions with high levels of both phenotypic and genetic diversity. Moreover studies should also be done on the maternal inheritance of PE content by direct and reciprocal crosses between toxic and non-toxic genotypes. A further development of the analysis with molecular markers can be obtained with the integration of the results obtained with different classes of markers and developing mapping populations for linkage analysis of toxicity associate markers.

\section{ACKNOWLEDGEMENT}

We would like to thank Dr. Daniel Gomez Sanchez of the Facultad de Ciencias Quimicas, Universidad Juarez del Estado de Durango (Durango, Mexico), for supplying seeds of several non-toxic Jatropha curcas accessions.

\section{REFERENCES}

Ambrosi GD, Galla G, Purelli M, Barbi T, Fabbri A, Barcaccia G (2010). DNA Markers and FCSS Analyses Shed Light on the Genetic Diversity and Reproductive Strategy of Jatropha curcas L. Diversity 10:810-836.

Baldini M, Raranciuc S, Vischi M (2012). Toxicity of Jatropha curcas L. as a biofuel crop and options for management. CAB Reviews 7,042:1-13. doi: 10.1079/PAVSNNR20127042

Basha S, Francis G, Makkar H, Becker K, Sujatha M (2009). A comparative study of biochemical traits and molecular markers for assessment of genetic relationships between Jatropha curcas L. germplasm from different countries. Plant. Sci. 176:812-823.

Botstein D, White RL , Skolnick M, Davis RW (1980). Construction of a genetic linkage map in man using restriction fragment length polymorphisms. Am. J. Hum. Genet. 32:314-331.

Boutin-Ganache I, Raposo M, Raymond M, Deschepper CF (2001). M13-tailed primers improve the readability and usability of microsatellite analyses performed with two different allele-sizing methods. Biotechniques 3:124-128.

Ceasar SA, Ignacimuthu S (2011). Applications of biotechnology and biochemical engineering for the improvement of Jatropha and biodiesel: a review. Renewable Sustain. Energy Rev. 15(9):51765185.

Commission of the European Communities (UE) (2007). Biofuels Progress Report. Report on the progress made in the use of biofuels and other renewable fuels in the Member States of the European Union. Communication from the commission to the Council and the European Parliament, Brussels, Belgium.

Dehgan B, Schutzman B (1994). Contributions toward a monograph of neotropical Jatropha: phenetic and phylogenetic analyses. Ann. Mo. Bot. Gard. 81:349-367.

Dehgan B, Webster G (1979). Morphology and infrageneric relationships of the genus Jatropha (Euphorbiaceae). Univ. Calif.
Publ. Bot. 74:1-73.

Felsenstein $\mathrm{J}$ (1985). Confidence limits on phylogenies: An approach using the bootstrap. Evolution 39:783-791

Francis G, Oliver J, Sujatha M (2013). Non-toxic jatropha plants as a potential multipurpose multi-use oilseed crop. Ind. Crop Prod. 42:397401.

Fukatsu E, Isoda K, Hirao T, Takahashi M, Watanabe A (2005). Development and characterization of simple sequence repeat DNA markers for Zelkova serrata. Mol. Ecol. Notes 5:378-380.

Haas W, Mittelbach M (2000). Detoxification experiments with the seed oil from Jatropha curcas L. Ind. Crop Prod. 12:111-118.

He W, King AJ, Awais Khan M, Cuevas JA, Ramiaramanana D, Graham IA (2011). Analysis of seed phorbol-ester and curcin content together with genetic diversity in multiple provenances of Jatropha curcas L. from Madagascar and Mexico. Plant Physiol. Biochem. 49:1183-1190.

Langella M (1999). Populations 1.2.30: Population genetic software (individuals or population distances, phylogenetic trees). http://bioinformatics.org/ tryphon/populations/

Makkar HPS, Becker K (2009). Jatropha curcas, a promising crop for the generation of biodiesel and value-added coproducts. Eur. J. Lipid Sci. Technol. 111:773-787.

Makkar HPS, Siddhuraju P, Becker K (2007). Plant Secondary Metabolites. In Methods in molecular biology, Humana Press, Totowa, New Jersey, pp 1-130.

Nei M, Tajima F, Tateno Y (1983). Accuracy of estimated phylogenetic trees from molecular data. J. Mol. Evol. 19:153-170.

Ovando-Medina I, Sánchez-Gutiérrez A, Adriano-Anaya L, EspinosaGarcía F, Núñez-Farfán J, Salvador-Figueroa M (2011b). Genetic Diversity in Jatropha curcas populations in the State of Chiapas, Mexico. Diversity 3(4):641-659.

Pamidimarri DV, Singh S, Mastan GS, Patel J, Reddy MP (2009). Molecular characterization and identification of markers for toxic and non-toxic varieties of Jatropha curcas L. using RAPD, AFLP and SSR markers. Mol. Biol. Rep. 36:1357-1364.

Peakall R, Smouse PE (2006). GenAIEx6: genetic analysis in Excel. Population genetic software for teaching and research. Mol. Ecol. Notes 6:288-295.

Phumichai C, Phumichai T, Kongsiri N, Wongkaew A, Sripichit P, Kaveeta R (2011). Isolation of 55 microsatellite markers for Jatropha curcas and its closely related species. Biol. Plant. 55(2):387-390.

Prasad L, Pradhan S, Das LM, Naik SN (2012). Experimental assessment of toxic phorbol ester in oil, biodiesel and seed cake of Jatropha curcas and use of biodiesel in diesel engine. Appl. Energy 93:245-250.

Rosado TB, Laviola BG, Faria DA, Pappas MR, Bhering LL, Quirino B, Grattapaglia D (2010). Molecular Markers Reveal Limited Genetic Diversity in a Large Germplasm Collection of the Biofuel Crop Jatropha curcas L. in Brazil. Crop Sci. 50:2373-2382.

Sahoo PK, Das LM (2009). Process optimization for biodiesel production from Jatropha, karanja and polanga oils. Fuel 88(9):15881594.

Schuelke M (2000). An economic method for the fluorescent labelling of PCR fragments. Nat. Biotechnol. 18:233-234.

Siddharth J, Sharma MP (2010). Prospects of biodiesel from Jatropha in India: a review. Renew and Sustain. Energy Rev. 14:763-771.

Sneath PHA, Sokal RR (1973). Numerical taxonomy - the principles and practice of numerical classification. (W. H. Freeman and Co. eds), San Francisco, USA. pp. 573.

Stephenson P, Bryan G, Kirby J, Collins A, Devos K, Busso C, Gale M (1998). Fifty new micro-satellite loci for the wheat genetic map. Theor. Appl. Genet. 97:946-949.

Sujatha M, Makkar H, Becker K (2005). Shoot bud proliferation from axillary nodes and leaf sections of non toxic Jatropha curcas L. Plant. Growth Regul. 47:83-90.

Tamura K, Peterson D, Peterson N, Stecher G, Nei M, Kumar S (2011). MEGA5: Molecular Evolutionary Genetics Analysis using maximum likelihood, evolutionary distance, and maximum parsimony methods. Mol. Biol. Evol. 28:2731-2739.

Tiwari AK, Kumar A, Raheman H (2007). Biodiesel production from Jatropha oil (Jatropha curcas) with high free fatty acids: an optimized process. Biomass Bioenergy 31:569-575. 
Wen M, Wang H, Xia Z, Zou M, Lu C, Wang W (2010). Development of EST-SSR and genomic-SSR markers to assess genetic diversity in Jatropha curcas L. BMC Res. Notes 3:42.

Wink M, Koschmieder C, Sauerwein M, Sporer F (1997). Phorbol esters of $J$. curcas - biological activities and potential applications. In: Biofuels and Industrial Products from Jatropha curcas.(Gubitz GM, Mittelbach M, Trabi M eds.) pp. 160-166.
Yadav K, Ranjan A, Mehar HA, Mantri S, Sawant S V, Tuli R (2011). EST-derived SSR markers in Jatropha curcas L.: development, characterization, polymorphism, and transferability across the species/genera. Tree Genet. Genomes 7:207-219. 